\title{
Character of adsorbed bovine serum albumin from adsorption enthalpies
}

\author{
Frank E. Filisko, Devi Malladi* and Sumner Barenberg ${ }^{\dagger}$ \\ Department of Materials Science and Engineering. The University of Michigan. Ann Arbor, Michigan 48109, USA \\ (Received 13 February 1986; revised 1 May 1986) \\ Presented at the 1985 Annual Meeting of the American Institute of Chemical Engineers (A/ChE) and used by permission of AlChE.
}

\begin{abstract}
Heats of adsorption of BSA onto polystyrene and polycarbonate were determined microcalorimetrically. The polymers were coated onto $50 \mathrm{~nm}$ alumina particles which were immersed in buffer for the measurements. Experimental variations to isolate the various component reactions of the integral heats included adsorption of native and denatured BSA from solution, adsorption onto substrates precoated with BSA, varying the thicknesses of adsorbed BSA by varying concentrations of the adsorbing solutions, and determining the denaturation energy by solution of the solid native and denatured BSA into a denaturing solvent.
\end{abstract}

Keywords: Adsorption, bovine serum albumin (BSA), proteins, heats of adsorption, microcalorimetry, denaturation

The interaction of proteins at interfaces is a common and important biological phenomenum. In particular when a nonbiological surface contacts whole blood, immediate adsorption of dissolved plasma proteins and other substances occurs onto the surface ${ }^{1}$. The events following this adsorption which ultimately results in thrombus formation are almost certainly related to the overall character of this adsorbed layer. The simple observation however that different materials have drastically different thrombogenic activity suggests that the characteristics of these layers are different for different materials.

For this and other reasons much research has been and is being devoted to characterizing this adsorbed layer and to understanding the driving forces responsible for this adsorption. The complexity has been illustrated by Norde and Lyklema ${ }^{2}$ who observed that negatively-charged polystyrene lattices adsorb negatively-charged proteins. Experimental methods commonly used in this regard include various spectroscopic and chromatographic techniques such as circular dichroism ${ }^{3}$, attenuated total internal reflectance spectroscopy ${ }^{4}$, ellipsometry $y^{5}$, infrared ${ }^{6}$ and Raman $^{7}$ spectroscopy, fluorescence spectroscopy ${ }^{8}, \mathrm{ESCA}^{9}$, and Fourier transform infrared spectroscopy ${ }^{10}$. Despite a large amount of research, there still exist many uncertainties concerning this adsorbed layer. Evidence has been presented to show that the adsorbed proteins denature ${ }^{11}$ while other evidence indicates that they remain in a native state ${ }^{4}$. Furthermore, some workers indicated that the adsorbed proteins were laid down in a rather random or haphazard fashion ${ }^{12,13}$ while others believed that the adsorbed proteins might arrange themselves in some sort of ordered arrangement $^{14,15}$ analogous to epitaxial crystallization. Finally

*Present addresses: National Semiconductor, Santa Clara, CA, USA and 'E.I. Dupont, Wilmington, DE, USA. evidence persists which suggests that the proteins may bond end-to-end on the surface ${ }^{14}$, may lay down flat on the surface $^{13}$, and also bond very strongly to the surface ${ }^{16}$. In this paper measurements of heats of adsorption of bovine serum albumin (BSA) onto two different polymeric surfaces are presented and discussed with regard to the above points.

The thermodynamics of adsorbed protein films have been treated theoretically by Levine ${ }^{17}$ and Norde and Lyklema ${ }^{18}$. An interesting feature of Levine's work is that he illustrated the side and end-on adsorption which might occur and suggested along with Chattoraj and Bull ${ }^{12}$ that the condensed or adsorbed phase may evolve to a surface crystalline-like state. Norde and Lyklema ${ }^{18}$ on the other hand attempted to separate out theoretically the various contributions to the adsorption enthalpy. They further concluded that the adsorption process was entropically driven. Experimentally, the enthalpies of adsorption by various proteins onto some surfaces were measured calorimetrically by Nyilas et al. ${ }^{19}$ and also by Norde and Lyklema ${ }^{20}$. The former work involved measurements of heats of adsorption of human albumin, fibrinogen, and $\gamma$.globulin onto carbon and glass powder adsorbents while the latter involved adsorption of albumin and ribonuclease onto charged polystyrene lattices. In these studies, a form of the sample is necessary such that it has an enormous surface area. This was accomplished in the former by using powders and in the latter by using lattices. Nyilas et $a .^{19}$ obtained their data by measuring the heats of adsorption of the protein-buffer solution onto the dry powder and subtracting from this the separately measured heats of adsorption of the buffer onto the dry substrate. Although fine in principle, the heats of adsorption of the buffer were much greater than those for the protein and this method involved taking small differences between two large 
numbers. Nyilas' measurements however gave net exothermic reactions, a result which may not be expected because of the speculated denaturation which is endothermic. Nyilas et al. ${ }^{19}$ speculated that the heat evolved from the formation of the protein-substrate bonds was greater than that adsorbed by denaturation. In Norde and Lyklema's work, a major improvement was made by dispersing the substrate in the same buffer solution as the proteins. Then by bringing the protein-buffer solution into contact with the latex-buffer suspension, the large heat of adsorption of the buffer onto the substrate was eliminated. Thus the effects measured were those associated with the protein-surface interaction, protein-protein interactions near the surface, displacement of previously adsorbed water, or ions if they occur, and intramolecular protein changes. However these lattices were prepared in a special manner ${ }^{21}$ and the surfaces contained fixed negative charges (due to sulphate groups) which prevented them from coagulating in suspension. These studies ${ }^{20}$ were performed on the latex particles at various temperatures, $\mathrm{pH}$ values and surface charges.

The results demonstrated that the enthalpy of adsorption could be exothermic or endothermic as a function of $\mathrm{pH}$ and surface charge. However, the magnitude of the endothermic adsorption enthalpies obtained were proportional to the latex particle surface charge, and for the lowest surface charged particles, the values were either zero or exothermic. Extrapolating this to particles or surfaces of zero charge, the adsorption enthalpies will be exothermic everywhere, an observation which would then be consistent with Nyilas et al.'s findings even though on different materials. The explanation of the data of Norde and Lyklema ${ }^{20}$ is as yet still not well understood.

The primary purpose of this study was to gain insight into the possible various component reactions involved in the integral heats of adsorption. For instance, the energy of denaturation could be estimated by taking the difference between the heats of solution of native protein and denatured protein into a denaturing solvent; the energies of forming surface-protein bonds can be estimated from heats of adsorption of denatured protein onto the surface; and the energies of protein-protein bonds could be approximated by measuring heats of adsorption of BSA onto a substrate which was coated with BSA.

\section{EXPERIMENTAL}

\section{Materials}

Albumin. Nondefatted bovine serum albumin (Fraction 5) from Sigma Chemical Co.

Alumina. Linde B $\gamma$-alumina of average particle size $(0.05 \mu \mathrm{m})$ from Fisher Scientific, Pittsburgh.

Polystyrene. Additive free transparent pellets from Dow Chemical Co., Midland, Michigan; $M W=3.1 \times 10^{5}$, $\mathrm{PDI}=2.78$ as obtained from g.p.c.

Polycarbonate. Merlon M-50 grade (J 1000) additive free, from Mobay Chemical Co., Pittsburgh.

Solvents. Chloroform and methylene chloride, certified ACS grade, from Fisher Scientific: 2-Mercapto-ethanol, certified class IIIA grade, from Fisher Scientific.
To obtain sufficient surface area, samples were prepared by solvent casting the polymers onto alumina powder. This was accomplished by making a solution containing a predetermined amount of polymer and adding this to the alumina powder. The criteria for the solution concentration, amount of alumina powder added, and amount of solution were that when added together the solution and powder formed a thick paste without any supernatant and after drying the coated alumina particles did not stick together. These conditions must be determined by trial and error but when the quantities are known, the average thickness of the coating on a particle could be estimated from the ratio of the weights of the polymer and alumina, the polymer and alumina densities, and the alumina particle size. After coating, the powders were dried at room temp. for $48 \mathrm{~h}$ and then in an oven overnight at $120^{\circ} \mathrm{C}$. For polystyrene the weight ratio of alumina to polystyrene used was $3.75: 1$, and for polycarbonate $5: 1$. A typical formulation follows: $2.2 \mathrm{~g}$ of a $12 \%$ solution of polystyrene in chloroform added to $1 \mathrm{~g}$ of alumina powder. Methylene chloride was used as the solvent for polycarbonate. The buffer used in all these measurements was a sodium acetate/hydrochloric acid buffer (pH 6.10) with an ionic strength of 0.05 .

Refractive index measurements were used to determine the amounts of protein adsorbed, i.e. the amount of protein remaining in solution after adsorption had occurred. These were measured with a Bausch and Lomb ABBE-3L refractometer.

The heats of adsorption and solution were determined with a Tian-Calvet type isothermal differential microcalorimeter. The instrumentation and solution techniques are described in detail elsewhere 22,23 . The technique used for the adsorption measurements was identical to that used for heats of dilution $^{24}$ except that the substrate immersed in the buffer was put inside the cuvette. The heat of dilution of the bufferprotein solution with buffer alone in the cuvette was found to be negligible.

\section{Experimental methods}

Heats of adsorption. The heats of adsorption were measured by loading the calorimeter cell with both the protein-buffer solution and the substrate immersed in the identical buffer solution, both being kept separated by the experimental setup design ${ }^{24}$. The cell was then introduced into the calorimeter and from that time it took about $1.5 \mathrm{~h}$ to attain equilibrium, i.e. before a measurement could be made. After this time the reaction was started by bringing the protein solution and the wetted substrate together. Agitation was performed in a controlled way ${ }^{24}$ to ensure complete contact of the substrate with the protein solution.

Conformational enthalpy of BSA. The magnitude of the heat of denaturation of BSA was estimated independently of adsorption measurements as follows. Firstly, an amount of solid native protein was dissolved, inside the microcalorimeter, into a denaturing solvent. The total heat of solution measured was the sum of the conformational enthalpy of the protein and various solvent-solute interaction terms. Secondly, the denatured solid protein was dissolved into the same denaturing solvent. The total heat of solution measured here does not contain a helix-coil transformation term because it was already denatured. However it does contain the same solvent-solute interaction term as in the native solution measurement. Furthermore, the final solution, in both cases should consist of denatured albumin in solution and they are then identical, independently of the initial solid state of the 
proteins. The difference between these two measurements should be the conformational enthalpy of the BSA.

\section{RESULTS AND DISCUSSION}

The integral enthalpy of adsorption is the sum of various component reactions which, as measured here, fi.e. adsorption of BSA from a buffer solution onto the substrate immersed in the buffer), should include energies associated with BSAsurface bond formation, with conformational changes of the BSA upon adsorption (if they occur), with displacement of previously adsorbed components from the buffer, and with possible unique morphologies which may develop upon adsorption. The following discussion presents the results of our studies to determine the magnitudes of the various component reactions.

\section{Conformational enthalpy of BSA}

The energy of denaturation of BSA could be independently determined by solution calorimetry as described earlier. Because the exact extent of denaturation in the solid state was not known nor the extent of denaturation in the solution, different denaturing solvents were used as well as different methods of denaturing the solid. The denaturing techniques used were sufficient to denature the protein but not to render the protein insoluble in the denaturing solvents used. Many denaturing techniques attempted did insolubilize the protein such that it only swelled in the solvents used, but this data is not presented here. A denaturing solvent containing mercaptoethanol was used to ascertain the significance of disulphide crosslinks and free $\mathrm{SH}$ groups on these measurements, i.e. mercapto-ethanol breaks disulphide crosslinks and irreversibly binds free SH groups. Table 1 illustrates the results of these measurements. The conformational energy of BSA, which is the difference in value before and after denaturation, ranges from $13.8 \times 10^{3}-22.1 \times 10^{3} \mathrm{~J} / \mathrm{kg}$ and gives an average value of $(17 \pm 3) \times 10^{3} \mathrm{~J} / \mathrm{kg}$. These values should only be considered estimates, however, since it is unlikely that the extent of denaturation in the different solvents and in the different denatured solids is identical and complete. This value was generally consistent with some values reported in the literature ${ }^{26}$. It, however, gives an idea of the magnitude of the enthalpy increment we are looking for if denaturation occurs upon adsorption.

\section{Energy of BSA-surface bond formation}

An estimate of this quantity was obtained by adsorbing denatured BSA from solution, thus minimizing conformational effects which might occur. This was accomplished by dissolving the BSA into a buffer solution containing $0.1 \mathrm{M}$ sodium lauryl sulphate ${ }^{25}$ which conformationally changes but does not precipitate the protein. The substrate was immersed in the identical solvent. There were at least two uncertainties in this approach. One was that the detergent was a surfactant and consequently more effectively wets the surface than water alone and may affect the BSA-surface bond. Another was that the values obtained would include energies associated with displacement of previously adsorbed buffer components if this displacement occurred. The heats of adsorption obtained from Figures 1 and 2 are $-330 \mathrm{~J} / \mathrm{kg}$ of powder) for polystyrene coated alumina and $-250 \mathrm{~J} /(\mathrm{kg}$ of powder) for polycarbonate coated alumina. The energies of ion displacement would be positive whereas those for bond formation between the protein and surface would be negative. The negative measured values indicated that either the BSA-surface bond was energetically stronger than buffer-surface bonds or that displacement of buffer components might not occur. Whatever the situation the heats of adsorption as measured here are integral and

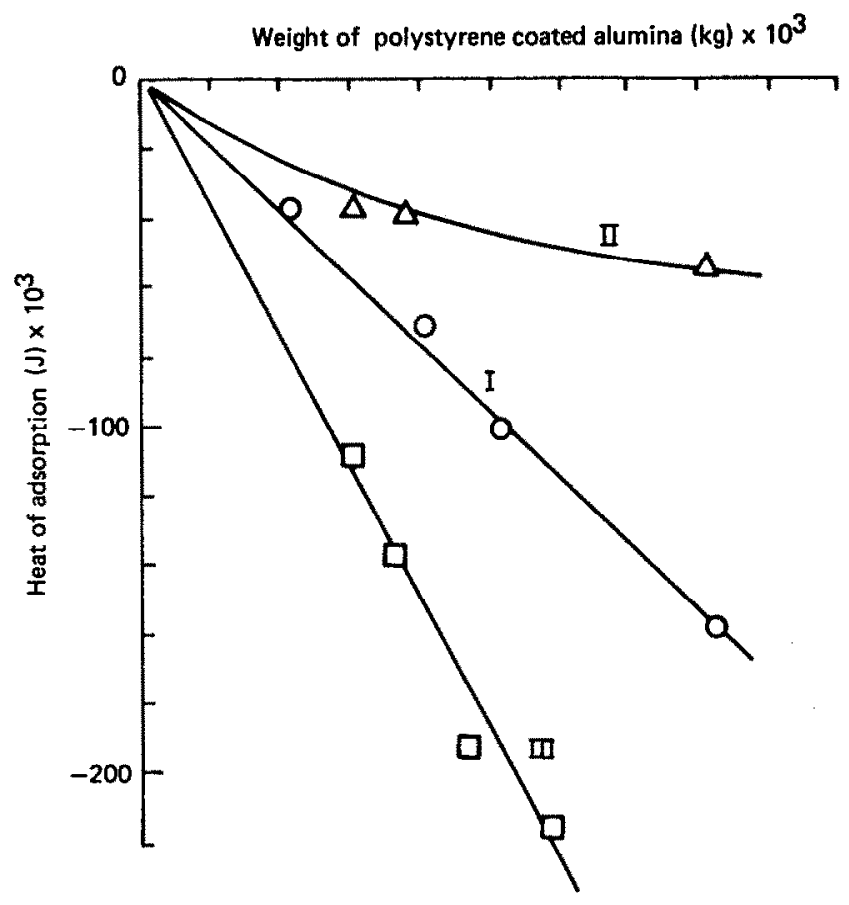

Figure 1 Heats of adsorption of BSA froma $2 \%$ solution onto a polystyrene coated alumina powder immersed in buffer. I. From native BSA in solution; II, from denatured BSA in solution; III, from native BSA in solution onto substrate precoated with BSA. (Max. error in calorimetric measurements $= \pm 3 \%$

Table 1 Heats of solution of native and denatured BSA in various denaturing solvents

\begin{tabular}{|c|c|c|c|}
\hline \multirow[t]{2}{*}{ Sample treatment } & \multicolumn{3}{|c|}{ Heats of solution $(\mathrm{J} / \mathrm{kg} \mathrm{BSA})^{\mathrm{a}}$} \\
\hline & $1 \%$ Acetic acid & $8 \mathrm{~m}$ Urea & $8 \mathrm{M}$ Urea $+0.01 \mathrm{M}$ mercapto-ethano \\
\hline Native & $-53.6 \times 10^{3}$ & $-57 \times 10^{3}$ & $-65.7 \times 10^{3}$ \\
\hline At $100^{\circ} \mathrm{C}$ for $0.5 \mathrm{~h}$ & & $-70.3 \times 10^{3}$ & \\
\hline $\begin{array}{l}\text { Precipitated from } 50: 50 \\
\text { acetone-water mixture; dried } \\
\text { at } 72^{\circ} \mathrm{C} \text { for } 15 \mathrm{~h}\end{array}$ & & $-71.6 \times 10^{3}$ & \\
\hline $\begin{array}{l}\text { Precipitated from boiling water: } \\
\text { dried at } 75^{\circ} \mathrm{C} \text { for } 15 \mathrm{~h}\end{array}$ & $-75.7 \times 10^{3}$ & $-74.5 \times 10^{3}$ & $-80.4 \times 10^{3}$ \\
\hline Held at $75^{\circ} \mathrm{C}$ for $1 \mathrm{wk}$ & $-71.6 \times 10^{3}$ & & \\
\hline
\end{tabular}

${ }^{\mathrm{a}} \mathrm{Max}$. error in calorimetric measurements $= \pm 3 \%$. 


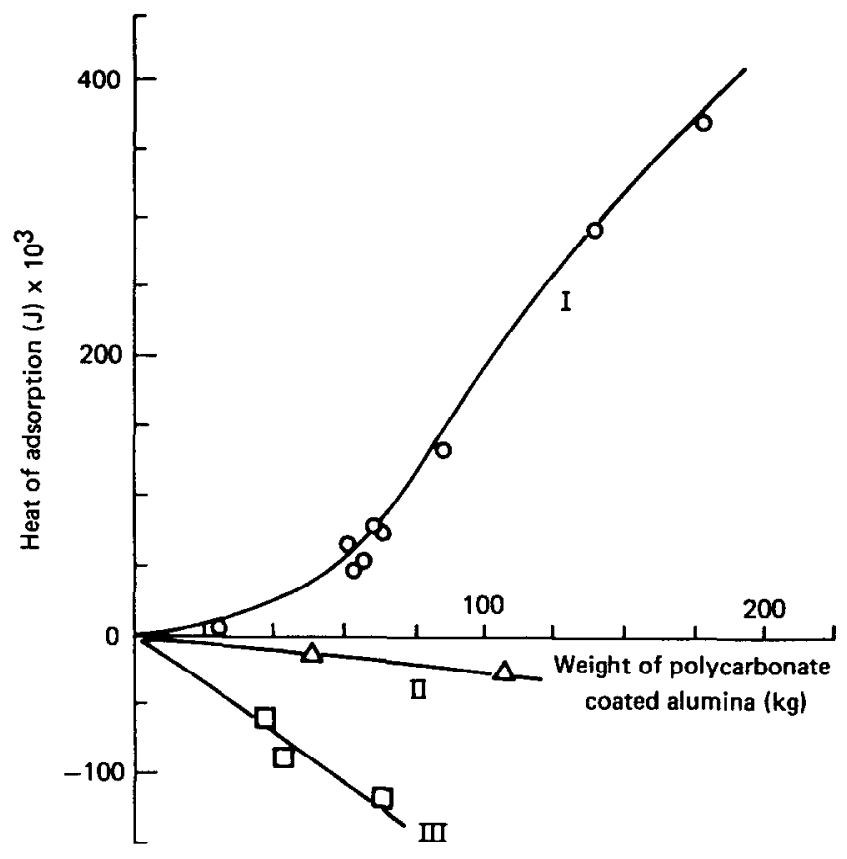

Figure 2 Heats of adsorption of BSA from a $2 \%$ solution onto a polvcarbonate coated alumina powder immersed in buffer. 1. From native $B S A$ in solution; II, from denatured BSA in solution; III, from native BSA in solution onto substrate precoated with BSA. (Max. error in calorimetric measurements $= \pm 3 \%$ ).

include the sum of all the reactions culminating in an adsorbed protein layer on the surface. The mechanisms involved, i.e. whether ion displacement occurs or not, should be similar whether the BSA adsorbed is native or denatured. The presence of the detergent restricts too broad a generalization of the data but does allow some interesting speculation on the data which follows.

\section{BSA onto polystyrene}

Figure 1 illustrates the integral heats of adsorption for BSA onto polystyrene coated alumina particles for three different situations. For all the data in this Figure the protein solution contained $2 \%$ BSA so that only a fraction of the protein was adsorbed. In situation I, native BSA in buffer was adsorbed onto the polystyrene substrate immersed in buffer. In situation II, denatured BSA in a buffer $+0.1 \mathrm{M}$ sodium lauryl sulphate solution was adsorbed onto the substrate immersed in an identical solution. As mentioned, the purpose of this variation was to minimize conformational enthalpies from the measurements as well as the possible entropic driving force for adsorption associated with the helix-coil transition. In situation III, the substrate was precoated with BSA (by immersing it in a $2 \%$ BSA-buffer solution) before being introduced into the instrument. The intent here was to eliminate enthalpy effects associated with the formation of protein-substrate bonds and with displacement of buffer components from the substrate surface upon adsorption. In comparing I and II, the most obvious difference would be the enthalpy contribution due to denaturation of the BSA in I. This could not occur for II, and if it did occur in I would introduce a positive heat and make I more endothermic. The data however shows clearly that $I$ is substantially more exothermic (i.e. negative) than II indicating that a significant exothermic reaction is occurring. A second consideration concerns the formation of BSA-surface contacts and possibly the displacement of preadsorbed buffer components.
If II can be considered to be a measure of the sum of these two effects, then the negative integral enthalpy implies that the energy of bond formation is greater than that of $\mathrm{H}_{2} \mathrm{O}$ /ion displacement. The net energy per BSA-surface bond formed however should be nearly the same for the native and denatured BSA. If it is assumed that the number of bonds formed is proportional to the amount of adsorbed protein contacting the surface (which should be roughly the same for both the native and the denatured BSA), then both should give nearly the same value. What occurred was that adsorption of native BSA evolved over 4 times as much heat as did the denatured material. To explain this difference based upon numbers of bonds alone would require the adsorbed native BSA to form about 4 times as many bonds per unit area as the denatured. It would however seem more likely that the denatured material would form more bonds because of conformational constraints on the native material.

On the other hand in situation III no surface-BSA bonds should form and no ions should be displaced from the substrate surface. This situation involves adsorption of native BSA onto preadsorbed BSA which would be expected to be fairly small as opposed to adsorption directly onto the substrate surface. However as shown, situation III is substantially more exothermic than either I or II. A possible explanation of III is that the more subtle adsorption (in terms of free energy) eliminates a positive or endothermic enthalpy component present in I, i.e. the positive enthalpy contribution from denaturation. Index of refraction measurements were used to determine that for $I$ and $I I, 55.3 \mathrm{mg} \pm 1 \%$ and $82 \mathrm{mg} \pm 1 \%$ BSA were adsorbed per gram of polystyrene coated alumina. Although a similar value was not determined for III, if we assumed a value equal to that for II, and if we add to III $-4600 \mathrm{~J} / \mathrm{kg}$ (as estimated from I) to take into account the fact that BSA-surface bonds did not form, then the difference between II and III would be about $+21 \times 10^{3}$ $\mathrm{J} /(\mathrm{kg}$ of BSA). This value was determined as if all the adsorbed BSA was denatured. If this were so then the integral heats of adsorption would be positive, not negative. Therefore an additional component to the integral enthalpy of adsorption is indicated which is large and exothermic.

In an attempt to further characterize the components of the integral heat of adsorption, a study was performed in which the thicknesses of the adsorbed protein layers were varied by varying the concentration of the adsorbing solution. The results are illustrated in Figure 3 . Included in this graph for comparison are the data from Figure 1 in which maximum surface coverage had occurred. As the thickness of the adsorbed layer decreases the heats of adsorption increase consistently to a positive value of about $+19 \times 10^{3} \mathrm{~J} /(\mathrm{kg}$ of BSA) for very thin layers, i.e. layers adsorbed from very dilute BSA solutions in which all the protein was adsorbed from the solution and complete surface coverage did not occur. To explain this data, it is reasonable to assume that for all the films in which complete surface coverage occurred, the amount of protein in direct contact with the substrate is the same and enthalpy contributions associated with this 'first' layer are the same. The observed enthalpy changes must then come from contributions associated with the 'outer' layers of adsorbed protein. This exothermic contribution to the heats of adsorption cannot then be due to surface contacts nor to denaturation. Further, as the films get thinner until only the 'first' layer remains, it was observed that the heats of adsorption were positive and in the magnitude expected for denaturation. If we speculate that for adsorption of denatured 


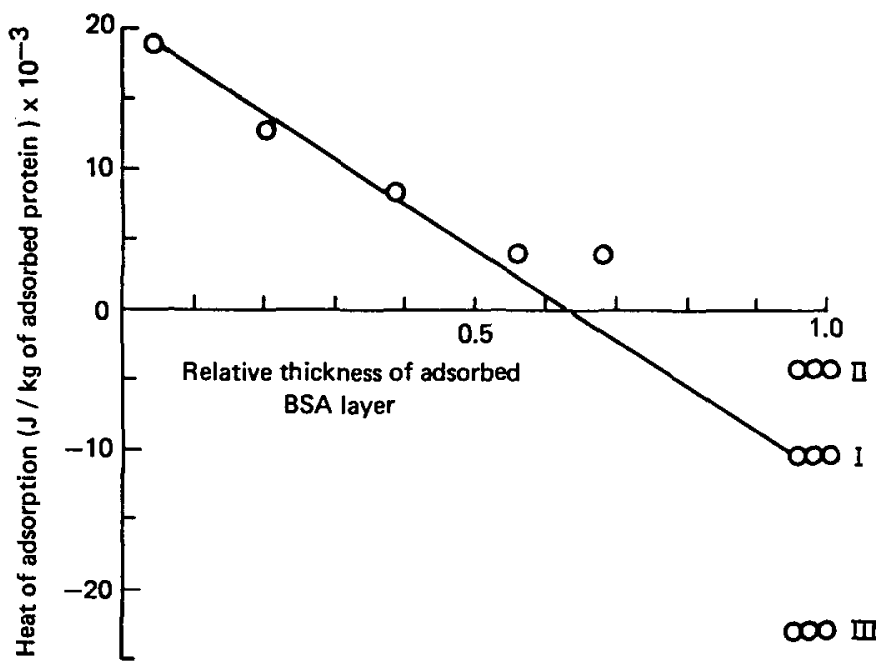

Figure 3 Specific heats of adsorption for BSA onto polystyrene coated alumina powder versus relative thickness of the adsorbed BSA. The amount of BSA adsorbed per particle or the thickness of the adsorbed layer is varied by varying the concentration of the adsorbing solutions. (Max. error in calorimetric measurements $= \pm 3 \%$ ).

BSA, all the heat evolved is due to surface contacts, and for the adsorption of native BSA onto BSA precoated substrate that the enthalpy due to surface contacts is eliminated, a possible model could be put forward which qualitatively could explain this data. The adsorbed BSA layer on polystyrene consists of an initial layer of denatured protein. In subsequent adsorption the BSA not only does not denature but also forms an ordered liquid crystalline array which when formed, could be responsible for the relatively large exothermic contribution to the integral heats of adsorption.

\section{BSA onto polycarbonate}

The data for the heats of adsorption of BSA onto polycarbonate coated alumina particles is illustrated in Figure 2. Again, the adsorbing solution contained $2 \%$ BSA so that only a fraction of it was actually adsorbed. The data bears some interesting similarities and a dramatic difference from the polystyrene data in Figure 1. The most obvious difference is that for adsorption of native BSA, the heats are completely positive (endothermic) as opposed to those for polystyrene which are negative. The values for the heat of adsorption per gram of substrate range from very small at $20 \mathrm{mg}$ of substrate to about $+2300 \mathrm{~J} / \mathrm{kg}$ at $140 \mathrm{mg}$ of substrate. It was determined that the coated polycarbonate substrates adsorbed about $133 \mathrm{mg}$ BSA per gm of substrate. Thus the $+2300 \mathrm{~J} / \mathrm{kg}$ of substrate) would give a value of $+17 \times 10^{3} \mathrm{~J} /(\mathrm{kg}$ of adsorbed BSA) which, despite many simplifications made, nonetheless is within the range of the magnitude of heats for protein denaturation ${ }^{26}$. This conclusion alone may seem presumptuous but if denatured protein is adsorbed, as previously discussed, the heats of adsorption become negative and small (exactly as for polystyrene). Thus if it is assumed that the denatured material forms only surface contacts whereas the native material forms surface contacts (which have a negative enthalpy) and denatures as well, the difference between these two gives a value of about $+19 \times 10^{3} \mathrm{~J} /(\mathrm{kg}$ of BSA) which is, interestingly, close to the $+21 \times 10^{3} \mathrm{~J} /(\mathrm{kg}$ of BSA) obtained for polystyrene.

As with polystyrene, the polycarbonate coated substrate was precoated with BSA, to eliminate surface contacts, and the resulting heats of adsorption were similar in both sign and magnitude, i.e. $-2 \times 10^{3} \mathrm{~J} /(\mathrm{kg}$ polystyrene substrate) and $-1.8 \times 10^{3} \mathrm{~J} /(\mathrm{kg}$ polycarbonate substrate). This data suggests a similar explanation for both materials, i.e. the protein adsorbed onto the BSA precoated substrates does not denature and also possibly forms an ordered liquid crystalline-like array.

\section{CONCLUSIONS}

The problem of understanding the mechanisms of protein adsorption and the character of the adsorbed proteins is immense. This is so because they vary not only with different materials and surface variations such as morphology and charge, but also with buffer, $\mathrm{pH}$, temperature, concentration and type of protein for single protein solutions, types and relative concentrations of proteins for multicomponent solutions, source and preparation of proteins, types and concentration of buffer ions, etc. Even the structure of albumin in solution has not been worked out. Despite these facts, isolated observations are nonetheless essential to obtain a better understanding of this phenomenon. In this paper we have presented results for the adsorption of a specific protein onto two different surfaces. Although we feel that these observations can be generalized far beyond our specific studies, this is not meant to be implied. Our explanation of the results for polystyrene is certainly consistent with the data and supportive of a model proposed by Brash and Lyman ${ }^{4}$.

The data for polycarbonate huwever sugyests immediately that this model cannot be generalized since it appears that all of the BSA adsorbed onto the wetted surface was denatured. This implies in addition that the chemical and/or morphological character of the substrate surface is essential in determining the character of the adsorbed protein layer.

\section{REFERENCES}

1 Brash, J.L. and Lyman, D.J., The Chemistry of Biosurfaces, Vol. 1, Marcel Dekker, Inc., New York, 1971, pp 177-232

2 Norde, W. and Lyklema, J., The adsorption of human plasma albumin and bovine pancreas ribonuclease at negatively charged polystyrene surfaces, J. Coll. Interface Sci. 1978, 66. 257

3 McMillin, C.R. and Waiton, A.G., A circular dichroism technique for the study of adsorbed protein structure. J. Coll. Interface Sci. 1974, 48. 345

4 Brash, J.L. and Lyman, D.J., Adsorption of plasma proteins in solution to uncharged hydrophobic polymer surfaces, J. Biomed. Mater. Res. $1969,3,175$

5 Morrissey, B.W., Smith, L.E. and Stromberg, R.R., Ellipsometric investigation of the effect of potential on blood protein conformation and adsorbance, J. Coll. Interface Sci. 1976, 56, 557

6 Morrissey, B.W. and Fenstermaker. C.A., Conformation of adsorbed $\gamma$-globulin and $\beta$-lactoglobulin, effect of surface concentration, Trans. Am. Soc. Art. Int. Organs 1976, 22, 278

7 Sutton, P., MS Thesis, Case Western Reserve University, Cleveland, Ohio, 1969

8 VanWagenen, R., Andrade, J.D. and Zdasuik, B., Advances in Chemistry Series (Eds S. Cooper and N. Peppas), American Chemical Society, New York, 1982, 199

9 Hanson, S.R., Harker, L.A., Ratner, B.D. and Hoffman, A.J., In vivo evaluation of artificial surfaces with a nonhuman primate model of arterial thrombosis, J. Lab. Clin. Med. 1980, 95, 289

10 Gendreau, R.M., Leininger, R.I. and Jakobsen, R., Molecular level studies of blood protein materials interactions, in Biomateria/s 1980, (Eds G. Winter, D. Gibbons and H. Plenk Jr.), John Wiley \& Sons, London, 1980

11 Horbett, T.A. and Hoffman, A.S., in Applied chemistry at protein interfaces (Ed. R.E. Baier) Adv. Chem. Ser. 145, ACS Washington, DC 1975, p 230.

12 Chattoraj, D.K. and Bull, H.B. Electrophoresis of adsorbed protein, J. Am. Chem. Soc. 1959, 81, 5128 
13 Bull, H.B., Adsorption of bovine serum albumin on glass, Biochem Biophys. Acta 1956, 19, 4674

14 Lyman, D.J., Brash, J.L., Chaikin, S.W., Klein, K.G. and Carini, M., The effect of chemical structure and surface properties of synthetic polymers on the coagulation of blood. II: Protein and platelet interaction with polymer surfaces, Trans. Am. Soc. Artif. Int. Organs $1968,14,250$

15 Geil, P.H., Barenberg, S.A. and Wong, W.M. Structure, morphology, and mechanical properties of bioplastics, in Proc. 1st Cleveland Symp. Macromolecules, (Ed. A.G. Walton), Elsevier, New York, 1977. p 105

16 Dillman, W.J. and Miller, I.F., Adsorption of serum proteins on polymer membrane surfaces, I.F., J. Coll. Sci. 1973, 44, 221

17 Levine, S.N., Thermodynamics of adsorbed protein films, J. Biomed. Mater. Res. 1969, 3, 83

18 Norde, W. and Lyklema, J., Thermodynamics of protein adsorption, J. Coll. Interface Sci. 1979, 71, 350

19 Nyilas, E., Chiu, T-H. and Turcotte, L.R., Government Report NIH-NO1HV-3-2917-4, 1977
20 Norde, W. and Lyklema, J., The adsorption of human plasma albumin and bovine pancreas ribonuclease at negatively charged polystyrene surfaces, J. Coll. Interace Sci. 1978, 66, 295

21 Furusawa, K., Norde, W. and Lyklema, J., A method of preparing surfactant free polystyrene latices of high surface energy, Kolloid- $Z Z$ Polym. 1972, 250, 908

22 Calvet, E. and Prat, H., Recent Progress in Microcalorimetry, Macmillan, New York, 1963

23 Maron, S.H. and Filisko, F.E., A modified Tian-Calvet microcalorimeter for polymer solution measurements, J. Macromol. Sci. 1972, B6-1. 57: Heats of solution and dilution for polyethylene oxide in several solvents, J. Macromol. Sci. 1972, B6-1, 79

24 Maron, S.H. and Filisko, F.E., Heats of solution and dilution of polyviny chloride in cyclohexanone and tetrahydrofuran, $J$. Macromol. Sci 1972, B6-2, 413

25 Putnam, F.W., Advances in Protein Chemistry, (Eds M.L. Anson, and J.T. Edsall), Vol. IV, Academic Press, New York, 1938

26 Tanford, C., Protein denaturation. Part B: the transition from native to denatured state, Adv. Protein Chem. 1968, 23, 121 